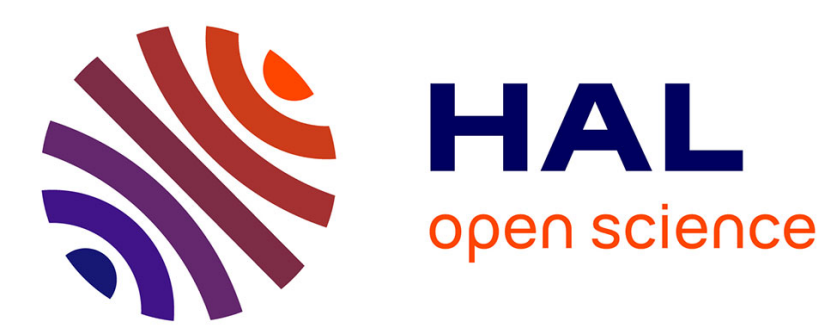

\title{
A PARAMETRIC SONAR PERFORMANCE CALCULATOR
}

\author{
Thomas Pederson
}

\section{To cite this version:}

Thomas Pederson. A PARAMETRIC SONAR PERFORMANCE CALCULATOR. Journal de Physique Colloques, 1979, 40 (C8), pp.C8-137-C8-139. 10.1051/jphyscol:1979824 . jpa-00219529

\section{HAL Id: jpa-00219529 https://hal.science/jpa-00219529}

Submitted on 1 Jan 1979

HAL is a multi-disciplinary open access archive for the deposit and dissemination of scientific research documents, whether they are published or not. The documents may come from teaching and research institutions in France or abroad, or from public or private research centers.
L'archive ouverte pluridisciplinaire HAL, est destinée au dépôt et à la diffusion de documents scientifiques de niveau recherche, publiés ou non, émanant des établissements d'enseignement et de recherche français ou étrangers, des laboratoires publics ou privés. 


\title{
A PARAMETRIC SONAR PERFORMANCE CALCULATOR
}

\author{
Thomas B. Pederson
}

Westinghouse Defense and Electronic Systems Center, Command and Control Division, P.0.Box 1897, Mail Stop 687, Blatimore, MaryZand 21203, USA.

\begin{abstract}
Résumé.- La prédiction des niveaux de source de frẽquence différence et des ouvertures du faisceau, engendrês par un émetteur sonar paramétrique est un processus compliqué, qui entraîne de nombreux calculs et l'emploi de plusieurs courbes et nomogrammes. Le savant ou l'ingénieur ayant souvent besoin d'une estimation rapide et facile de ces paramètres, on a mis au point un calculateur de type règle à calcul destiné à aider à la conception d'un tel êmetteur. Le calculateur donne des valeurs précises pour des réseaux paramétriques fonctionnant en régime non-saturé en utilisant les équations développêes pour ce cas par F.H. FENLON. Cette étude décrira les hypothèses utilisées pour la rẻalisation des échelles ainsi que les limitations à prendre en compte lors de l'emploi du calculateur.

Abstract.- Predicting the difference frequency source levels and beamwidths which will be developed by a given parametric sonar projector is a somewhat complicated procedure involving a number of calculations and the use of several curves or nomograms. Since a scientist or engineer often needs a quick and easy estimate of these parameters, a slide-type calculator was developed as a design aid. The calculator yields accurate values for arrays operating in the unsaturated regime by using equations developed by F.H. Fenlon for this case. In this paper the assumptions used in the preparation of the scales and the imitations to be kept in mind while using the calculator will be described.
\end{abstract}

1. Introduction and background.- When a scientist is using or considering the use of a parametric sonar he will need to be able to determine the source level and beamwidth at the difference frequency. Unfortunately these quantities must be calculated by the use of equations which are somewhat complex. A number of investigators have developed equations for calculating source level and beamwidth at a parametric sonar's difference frequency or have developed families of curves, nomographs and other aids to help the sonar engineer determine these quantities. In this paper, a slide-type calculator is introduced that should prove to be a useful design tool. The philosophy followed in this design will be presented along with explanations regarding its use. 2. Parametric gain.- The entire front face of the slide calculator has been devoted to the calculation of difference frequency source level in the form of parametric gain. This is simply the difference between the source levels at the difference and mean primary frequencies, that is :

$\mathrm{G}=\mathrm{SL} L_{-}-\mathrm{SL}_{0}$

where :

$G \quad=$ parametric gain

$\mathrm{SL}_{-}=$difference frequency source leve 1

$\mathrm{SL}_{0}=$ mean primary source leve $\mathrm{I}$

The equation developed by Dr. F.H. Fenlon, currently

with ARL-Penn State, for the difference frequency source level of a parametric source $/ 1 /$ is :

$$
\begin{aligned}
S L_{-}=20 & \log _{10}\left(\bar{P}_{0} r_{0}\right)-20 \log _{10}\left(\frac{\Delta}{\Delta}\right) \\
& +20 \log _{10}\left\{\begin{array}{ll}
\sqrt{2} & I_{1}\left(X_{1}\right) I_{1}\left(X_{2}\right) \\
\overline{\bar{X}_{0}} & I_{0}\left(X_{1}\right) I_{0}\left(X_{2}\right)
\end{array}\right\}
\end{aligned}
$$

where :

$\overline{\mathrm{P}}_{0}=$ total rms primary amplitude at the source

$r_{0}=$ Rayleigh distance

$f_{0}=$ mean primary frequency

$f_{-}=$difference frequency

$\Delta=E_{1}\left(\alpha_{T} r_{0}\right) \exp \left\{\alpha_{T} r_{0}\right\}$ where $\alpha_{T}=2 \alpha_{0}-\alpha_{-}=$total attenuation coeffi-

$\Delta^{\prime}=E_{1}\left(\alpha_{T} r_{0} \frac{f_{0}}{f_{-}}\right) \exp \left\{\alpha_{T} r_{0} \frac{f_{0}}{f_{-}}\right\}$

$E_{1}(y)=\int_{y}^{\infty} \frac{1}{x} e^{-x} d x$

$\bar{X}_{0}=\frac{\beta k_{0} \bar{P}_{0} r_{0}}{\rho_{0} C_{0}} \Delta$

where $: B=1+\frac{B}{2 A}=$ nonlinear parameter for liquids $k_{0}=2 \pi f_{0} / c_{0}=$ mean primary wave number

$c_{0}=$ small signal speed of sound

$\rho_{0}=$ density of the medium

$x_{1,2}=\frac{\sqrt{2} \beta k_{0} P_{0} 1,2 r_{0}}{\rho_{0} c_{0}}$

$\mathrm{I}_{0}, \mathrm{I}_{1}=$ modified Bessel functions. 
Unfortunately this equation has proven to be too complex for evaluation on a slide-type calculator. However, if we restrict ourselves to primary source levels below the levels where shock waves begin to develop, i.e., to the unsaturated regime, the equations simplify immensely. This is not too severe a restriction as most current parametric sonars operate in this regime. The simplification occurs because $x_{0}, x_{1}, x_{2} \ll 1$ in this region and the equation for parametric gain becomes :

$G=S L_{0}^{*}-20 \log _{10} \frac{f_{0}}{f_{-}}+20 \log _{10} \Delta^{\prime}-287$

where $S L_{0}^{*}=S L_{0}+20 \log _{10} f_{0}$

This is the equation solved on the front face of the calculator.

a. Rayleigh Distance, $r_{0}$

The Rayleigh distance at the mean primary frequency is the straightforward calculation normally used,

$r_{0}=A / \lambda_{0}=A c_{0} / f_{0}$

where $A=$ array area

$\lambda_{0}=$ wavelength at the mean primary frequency

$c_{0}=$ small signal sound speed

Sound speeds of 1481 and $1520 \mathrm{~m} / \mathrm{sec}$ were used for fresh and sea water, respectively.

\section{b. Absorption Coefficients}

The ShuTkin and Marsh /2/ equations were used in the formation of the absorption scales, namely:

For fresh water : $\alpha=2.68 \times 10^{-2} \frac{f^{2}}{f_{T}}$

and for sea water :

$\alpha=\left\{\begin{array}{l}\frac{0.1 f^{2}}{1+f^{2}}+\frac{40 f^{2}}{4100+f^{2}} \quad \text { for } f<5 \mathrm{kHz} \\ 1.86 \times 10^{-2} \frac{S f_{T} f^{2}}{f_{T}^{2}+f^{2}}+2.68 \times 10^{-2} \frac{f^{2}}{f_{T}} \text { for } f>5 \mathrm{kHz}\end{array}\right.$

where $f_{T}=21.9 \times 10^{6-1520 /(T+273)}$

$\mathrm{T}=$ temperature

$S=$ salinity in ppt

A temperature of $10^{\circ} \mathrm{C}\left(50^{\circ} \mathrm{F}\right)$ and a salinity of sea water of 35 ppt were the values used in the preparation of these scales.

c. Effective Array Length $\Delta^{\prime}$

The parameter $\Delta^{\prime}$, sometimes called effective array length, is given by :
$\Delta^{\prime}=E_{1}\left(\alpha_{T} r_{0} \frac{f_{0}}{f_{-}}\right) \exp \left(\alpha_{T} r_{0} \frac{f_{0}}{f_{-}}\right)$

where $E_{1}(X)=\int_{X}^{\infty} \frac{1}{Z} e^{-z} d z$

The exponential integral was evaluated using numerical techniques $/ 3$ / to generate the scale for calculating $20 \log _{10} \Delta^{\prime}$. Equivalent array length can also be used to determine the approximate nonlinear interaction range, i.e., the distance required for the difference frequency souce level to build up to its ultimate value (the value predicted by the calculator). The product of equivalent array length, the Rayleigh distance, and the downshift ratio will yield the approximate interaction range,

$r_{i} \approx \Delta^{\prime} r_{0} \frac{f_{0}}{f_{-}}$

d. Scaled Primary Source Level $\mathrm{SL}_{0}^{*}$

The scaled primary source level is simply:

$S L_{0}^{*}=S L_{0}+20 \log _{10} f_{0}$

and is evaluated in a straightforward manner on one of the front side scales.

\section{e. Parametric Gain}

The last scale on the front face of the calculator evaluates :

$G=S L_{0}^{*}-20 \log _{10} \frac{f_{0}}{f_{-}}+20 \log _{10} \Delta^{\prime}-287$

which gives the difference frequency source level since $G=S L_{-}-S L_{0}$.

3. Directivity and beamwidth.- On the reverse side of the calculator there are scales for calculating the approximate directivity index and beamwidth at the difference frequency.

\section{a. Directivity Index}

The directivity index of the difference frequency beam will be very close to the directivity index of the mean primary frequency beam pattern so the equation used for this is :

$D I=10 \log _{10} \frac{4 \pi A f_{0}^{2}}{c_{0}^{2}}$

and again, small signal sound speeds of 1481 and $1520 \mathrm{~m} / \mathrm{sec}$ were used for fresh and sea water, respectively.

\section{b. Beamwidth}

The half-power beamwidth is given by one of two equations, depending upon whether the array is spreading loss limited or absorption limited. 
For an array which is spreading loss limited the beamwidth is given by :

$\theta_{3 \mathrm{~dB}}=\left\{\begin{array}{cl}2 \sin ^{-1} \frac{2.7 c_{0}}{2 f_{0} d} & \begin{array}{l}\text { for a rectangular or } \\ \text { square array }\end{array} \\ 2 \sin ^{-1} \frac{c_{0}}{2 f_{0} d} & \text { for a circular array }\end{array}\right.$ where $d=$ side length or diameter as appropriate and for an absorption limited array it is :

$\theta_{3 \mathrm{~dB}}=4 \sqrt{\frac{\alpha_{\mathrm{T}} \mathrm{C}_{0}}{4 \pi \mathrm{f}_{-}}}$

for square or circular arrays.

Small signal sounds speeds of 1481 and 1520 $\mathrm{m} / \mathrm{sec}$ were used in the preparation of the scales.

Whether the array under consideration is spreading loss or absorption limited the beamwidth can be found by obtaining values from both scales and choosing the larger. This will be the appropriate value.

4. Critical source level $\mathrm{SL}_{\mathrm{c}}$ - The critical source level is the mean primary source level at which shock waves begin to form. At source levels above this level the equations being soived on the front face of the calculator no longer apply. Actually, since the accuracy becomes worse the nearer $\mathrm{SL}_{0}$ comes to $\mathrm{SL}_{\mathrm{c}}$, the results should be treated with caution when $S L_{0}$ is within, say 3 or $4 \mathrm{~dB}$ of the critical level (see figure 1). The equation which was used to calculate this quantity /1/ :

191.1 in fresh water $S L_{C}=10 \log _{10} L-20 \log _{10} f_{0}+192.2$ in sea water and the parameter $L$ is the solution to :

$\exp \left(-\frac{\pi}{2 L \beta}\right)=4.5\left(\frac{\alpha_{0} r_{0}}{\beta L}\right)$$$
\text { where } \beta=\text { nonlinearity parameter }=3.8 \text { for water }
$$$$
\begin{gathered}
3.6 \text { for fresh } \\
\text { water } \\
3.8 \text { for sea } \\
\text { water }
\end{gathered}
$$

The transendental equation for $L$ was solved using interative techniques and the results for various $\alpha_{0} r_{0}$ values included as a separate scale on the reverse side. The scale for $\mathrm{SL}_{c}$ is immediately below it and completes the solution.

5. Conclusions. - It is hoped that this calculator will prove to be a handy tool for engineers and scientists involved in finite-amplitude sonar. It is intended to give them an easy way to quickly estimate parametric conversion efficiencies, beamwidths and the like which were previously somewhat inconvenient to obtain.

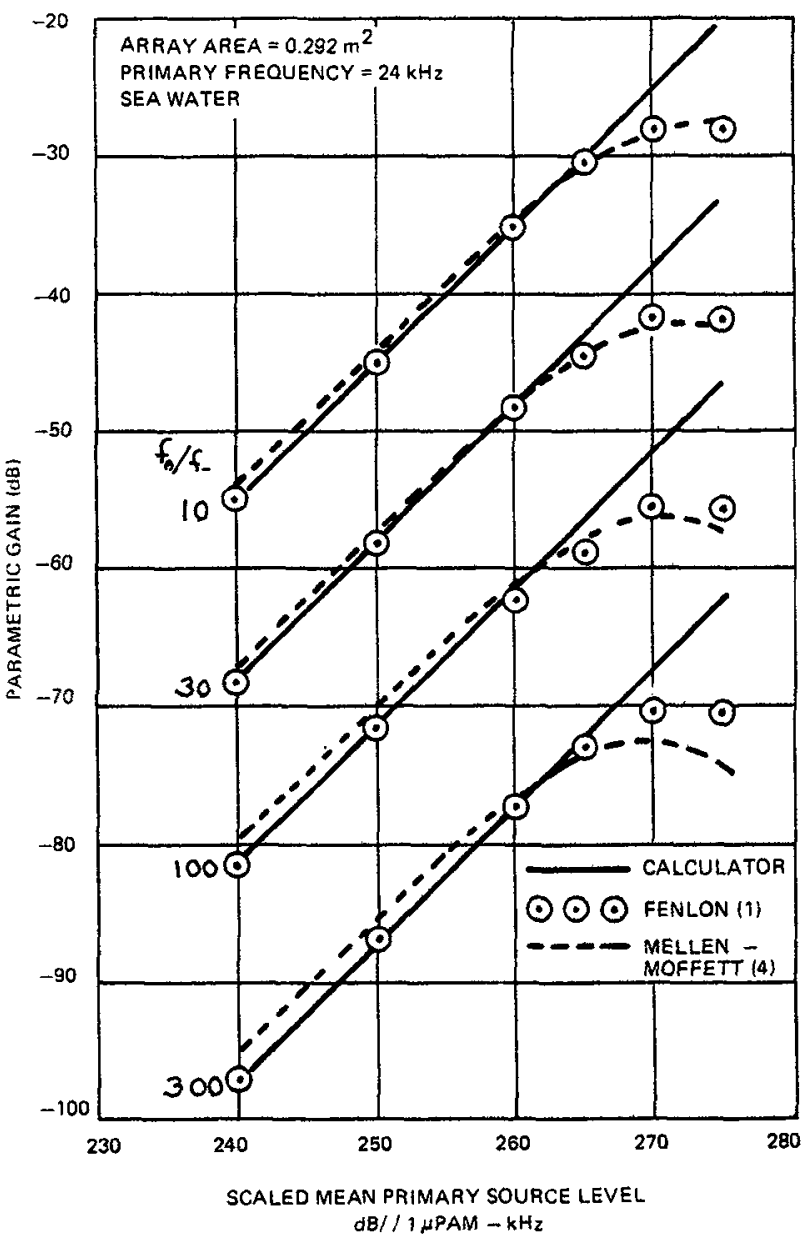

Fig. 1 - Comparison of theoretical results

References

/1/ Fenlon, F.H., "Parametric Scaling Laws", Westinghouse Report 74-9M7-NONLN-R2, August 22, (1974).

12/ Urick, R.J., "Principles of Underwater Sound (Second Edition)", McGraw-Hill Book Company, New-York, 1975.

13/ Abramowitz, M. and Stegun, 1.E.(Ed)., "Handbook of Mathematical Functions", NBS Applied Mathematics Series 55, 1964.

14/ Mellen, R.H. and Moffett, M.B., JASA 61 (1977) 25-337. 